\title{
WestVirginiaUniversity
}

THE RESEARCH REPOSITORY @ WVU

Graduate Theses, Dissertations, and Problem Reports

2015

\section{External Hyperlinking Practices in Print-based and Online-native News Sites}

\author{
Sarah K. Wisniewski
}

Follow this and additional works at: https://researchrepository.wvu.edu/etd

\section{Recommended Citation}

Wisniewski, Sarah K., "External Hyperlinking Practices in Print-based and Online-native News Sites" (2015). Graduate Theses, Dissertations, and Problem Reports. 6964.

https://researchrepository.wvu.edu/etd/6964

This Thesis is protected by copyright and/or related rights. It has been brought to you by the The Research Repository @ WVU with permission from the rights-holder(s). You are free to use this Thesis in any way that is permitted by the copyright and related rights legislation that applies to your use. For other uses you must obtain permission from the rights-holder(s) directly, unless additional rights are indicated by a Creative Commons license in the record and/ or on the work itself. This Thesis has been accepted for inclusion in WVU Graduate Theses, Dissertations, and Problem Reports collection by an authorized administrator of The Research Repository @ WVU. For more information, please contact researchrepository@mail.wvu.edu. 


\title{
External Hyperlinking Practices in Print-based and Online-native News Sites
}

\author{
Sarah K. Wisniewski \\ Thesis submitted \\ to the Reed College of Media \\ at West Virginia University
}

in partial fulfillment of the requirements for the degree of

Master of Science in

Journalism

\author{
Dana Coester, M.A., Chair \\ Bob Britten, Ph.D. \\ Mary Kay McFarland, M.A. \\ Justin Ellis \\ Department of Journalism
}

Morgantown, West Virginia

2015

Keywords: hyperlinks, Web 2.0, print media, digital native Copyright 2015 Sarah K. Wisniewski 


\section{ABSTRACT \\ External Hyperlinking Practices in Print-based and Online-native News Sites}

\section{Sarah K. Wisniewski}

This paper describes the differences in the use of external hyperlinks between print-based and online-native news sites. External hyperlinks are links that direct the user to a page outside the original domain, such as the Huffington Post including a link to Wikipedia. A subcategorization of online-native sites into three distinct waves based on launch dates and corresponding to recent transitions in communications technology is proposed. A quantitative content analysis of hyperlinks embedded in the text of articles from print-based, second-wave, and third-wave news sites in 2005, 2010, and 2014 suggests that print-based and online-native news sites do use external hyperlinks differently. Online-native sites appear to use external hyperlinks substantially more than print-based sites do. Print-based sites use more internal than external links, while online-native sites use more external than internal links. External hyperlink usage in secondwave online news sites did not change significantly over the course of the study, but the change in print-based external hyperlink usage is inconclusive. 
Table of Contents

Introduction

Theoretical Basis

1

Literature Review

4

Research Purpose and Hypotheses 15

Methodology 16

Results 19

Discussion 26

Limitations and Further Research 32

Conclusion $\quad 34$

References $\quad 35$

Appendix 1: Hyperlink Study Code Book 42

Appendix 2: Table - Summary of Frequency Data 46 


\title{
EXTERNAL HYPERLINKING PRACTICES
}

\author{
External Hyperlinking Practices in Print-based \\ and Online-native News Sites
}

Online news has been the new reality of the news industry since 2005 , if not earlier. News organizations first began offering news online in the 1980s (Garrison, B. \& Messner, M., 2009), and the number of newspapers offering online versions spiked after 1993 with the introduction of Mosaic, the first graphical web browser (Boczkowski, 2004; Curtis, 2013). Those first online newspapers tended to be direct copies of their print counterparts, with little to no interactive features, hyperlinking, or multimedia (van der Wurff et al., 2008). The content was often "shovelware" (Nguyen, 2008), or print content 'shoveled' onto the web without embellishment or adaptation. The early 2000s saw online content beginning to be tailored for the web. News blogs also took off in the early 2000s when access to the internet turned anyone with a keyboard into a publisher (Curtis, 2013; Weber, 2012). Social media was just beginning to explode, with Friendster in 2002, MySpace and LinkedIn in 2003, and Facebook in 2004 (Curtis, 2013). The 2004 presidential election coverage marked a major shift from repurposed print content to interactive Web 2.0 elements meant to engage users, such as chats, forums, blogs, and user-generated content (Garrison, B. \& Messner, M., 2009).

Web content has three main distinctive elements: hyperlinks, interactivity, and multimedia (Garrison, B. \& Messner, M., 2009; Larsson, 2013; van der Wurff et al., 2008), with hyperlinks perhaps the chief of the three (De Maeyer, 2012; De Maeyer, 2013). Hyperlinks are the very structural elements of the internet, connecting websites to other websites to form the online network or ‘web’ (Garrison, B. \& Messner, M., 2009). Tim Berners-Lee, inventor of and champion for the World Wide Web, envisioned an open exchange of information administrated for the good of the global public (Berners-Lee, 2014). At the heart of the web is the assumption 


\section{EXTERNAL HYPERLINKING PRACTICES}

that every web address is equal and can be accessed through links from other content (BernersLee, Shadbolt, \& Hall, 2006). An organization's use of external hyperlinks, or hyperlinks to other pages outside their own second-level domain, is indicative of that site's adaptivity to the web as a whole. External hyperlinks also build relationships with other organizations on the web, which draws web traffic through reciprocated links on other organizations' web sites (Weber, 2012). In short, external hyperlinks to and from a site are the measure of success on the internet (Garrison, B. \& Messner, M., 2009, p. 396).

Despite the significance of hyperlinks to online communication, the research overwhelmingly indicates that online news outlets are only linking among their own articles, not to resources outside their own domain (Carpenter, 2010; De Maeyer, 2012; Dimitrova, ConnollyAhern, Williams, Kaid, \& Reid, 2003; Larsson, 2013; Nguyen, 2008). For instance, in a case study conducted by Dimitrova et al. (2003) examining the Timothy McVeigh execution coverage, some news sources included hyperlinks to more of their own coverage, but the vast majority did not include links to another news organization's coverage, to organizations with a stance on the death penalty, or to government or other legal documents related to the case. Van der Wurff et al. (2008) found that, while the use of online features overall improved from the 1990s to 2003, hyperlinks remained underutilized with 91 percent of hyperlinks in 2003 still being internal. Barnhurst (2010) noted that external hyperlinks nearly vanished between 2001 and 2005, dropping to only two in the entire sample, even though the total number of stories using hyperlinks grew. Nguyen (2008) speculates that traditional news outlets in the 1990s and early 2000s perceived external hyperlinks as an indirect threat to their offline products, but research has not produced a conclusive reason why external hyperlinks in news articles are so 


\section{EXTERNAL HYPERLINKING PRACTICES}

scarce (Chang, Southwell, Lee, \& Hong, 2012; Himelboim, Chang, \& McCreery, 2010; Larsson, 2013).

This study will begin to answer that question by applying innovation diffusion theory (IDT) to the practice of external hyperlinking in order to identify news sources that already use external hyperlinks and their possible influence on other news sources that have been more reluctant to use external hyperlinks. The researcher hypothesizes that news sites that originated online will use external hyperlinks more often than news sites produced by traditional print media and may in fact be significant players in diffusing external hyperlinking to the traditional news media. 


\section{EXTERNAL HYPERLINKING PRACTICES}

\section{Theoretical Basis}

The absence of hyperlinks in news articles may be related to hyperlinks' unique position at the nexus of news and technology: A hyperlink is both an information item and a technology. The news industry has used gatekeeping theory to describe how news items reach the public ear since White's (1950) study of a wire editor's news selection criteria. Gatekeeping is “the process by which the vast array of potential news messages are winnowed, shaped, and prodded into those few that are actually transmitted by the news media" (Shoemaker, Eichholz, Kim, \& Wrigley, 2001, p. 233). Shoemaker and Reese (1996) proposed a hierarchy of various forces ranging from institutional factors to professional routines to individuals that influence whether a news item reaches publication. Dimitrova et al. (2003) applied gatekeeping theory to hyperlinking: "The decision about which story threads or other websites are offered by an individual newspaper's Web page is, in fact, an exercise of an online newspaper's gatekeeping authority" (p. 404). Before a hyperlink reaches publication in a news article, it must pass through all the same gates that any other news item must, including the news routines of the particular news outlet and the news industry as a whole, such as whether that news outlet uses external hyperlinks. These routine forces are highly influential, more so than any one individual's preferences (Shoemaker et al., 2001).

Innovation diffusion theory describes how an innovation is adopted or, in gatekeeping terms, becomes routinized. Diffusion is "the process in which an innovation is communicated through certain channels over time among the members of a social system" (Rogers, 2003, p. 5). An innovation is "an idea, practice, or object that is perceived as new by an individual or other unit of adoption" (Rogers, 2003, p. 12). An innovation may not be objectively new, as long as it 


\section{EXTERNAL HYPERLINKING PRACTICES}

is new to those who are considering adopting it. For instance, hyperlinks are as old as the web itself, but the practice of linking to external sites may be new to traditional news media.

Innovation diffusion research began at Iowa State University when Ryan and Gross (1943) noted a distinct S-curve in the pattern of Iowa farmers' adoption of hybrid corn seed. Repeated diffusion studies across a range of fields from public health to communications have found the same predictable S-curve distribution by plotting the number of adopters on a cumulative frequency basis (Rogers, 2003). Initially only a few venturous individuals adopt the innovation, then the numbers begin to climb (Figure 1). When a critical mass (Rogers, 2003, p. 343) of adopters is reached, adoption takes off and grows rapidly. Eventually the growth slows as fewer and fewer are left who have not adopted, and finally the S-curve levels out as the innovation saturates the system and the diffusion process completes. The diffusion period from initial adoption to system saturation varies depending on the system and the innovation but can range from weeks or months to

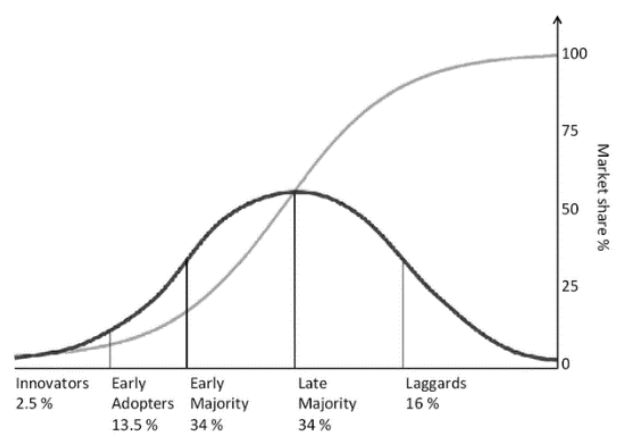

Figure 1: Sample graph showing the typical cumulative frequency S-curve and the corresponding normal bell curve distribution of adopter categories. Via ondigitalmarketing.com years.

In the classic model, the diffusion process begins when an innovation is introduced into a system via a change agent sent by a change agency. A change agency is an outside group who has an interest in the diffusion of a particular innovation in a particular system. A change agent is sent by the agency into a system to influence innovation decisions in a direction deemed desirable by the change agency (Rogers, 2003). In some cases, however, the process is decentralized, with the innovation arising from innovators within the system and spreading 


\section{EXTERNAL HYPERLINKING PRACTICES}

through peer networks as peers take on the role of change agents (Rogers, 2003). The innovation diffuses as more potential adopters see an advantage in the innovation and receive enough information to reduce the risk associated with it. The readiness with which one adopts an innovation is determined largely by one's level of risk tolerance. As more people adopt, the risk associated with adoption decreases, so more individuals feel comfortable adopting. Adopters are grouped into five categories based on the relative time at which they adopt an innovation compared to the other members of their system: innovators, early adopters, early majority, late majority, and laggards. Adopter category distributions follow a normal bell-shaped curve over time, resulting in the normal S-curve described above (Rogers, 2003, p. 275). Organizations, such as news outlets, adopt innovations in roughly the same way that individuals do and follow the same S-curve (Rogers, 2003).

If, as in the case of external hyperlinking in news articles, the innovation is not diffusing, it suggests one or both of two issues. First, the level of risk may still be higher than most of the individuals or organizations in the system are willing or able to tolerate. This is likely due to a lack of information: the potential adopter is unable to foresee the innovation's effect, whether positive or negative. Second, the apparent advantage may not be attractive enough to elicit change. This barrier is particularly common in organizations, because organizational structure by nature lends itself to stability rather than change (Rogers, 2003). Both of these problems can be helped by change agents who demonstrate the effectiveness and desirability of the innovation. The present study applies IDT in order to identify the roles of print-based and online-native news sites in the diffusion process of external hyperlinking within the system of the news industry.

Innovation diffusion theory has already been applied to media and communications in numerous ways. In their survey of innovation diffusion research within communications, 


\section{EXTERNAL HYPERLINKING PRACTICES}

Srivastava and Moreland (2012) go so far as to suggest that the communications field adopt the theory to help the field establish its identity. The diffusion process does depend heavily on communications from mass media to interpersonal at nearly every stage (Rogers, 2003), and many of the latest innovations have been in communication technologies (Srivastava \& Moreland, 2012), so the theory and field are well matched. Innovation diffusion theory has been used to explain the spread of public awareness of blogs (Hogg, Lomicky, \& Hossain, 2008), the shift in perception of mobile phones from phones to multimedia devices (Westlund, 2008), and the spread of a neologism via Twitter (Squires, 2014). Specifically related to news, a study found that news stories diffuse through social media along approximately the same S-curve predicted by IDT (Ma, Lee, \& Goh, 2012). Another study examined what factors influenced young adults' adoption of mobile news consumption (Chan-Olmsted, Rim, \& Zerba, 2013). 


\section{EXTERNAL HYPERLINKING PRACTICES}

\section{Literature Review}

External hyperlinks fulfill a number of traditional journalistic principles that should earn them space in online news articles. They allow for greater depth of reporting (De Maeyer, 2012; Larsson, 2013) without costing the news outlet space or reporting effort. Reporters can "do what [they] do best, link to the rest" (Jarvis, 2007). External hyperlinks have been shown to increase the net page views a site receives (Weber, 2012). Hyperlinks also increase the perceived credibility of a news story (Borah, 2014). Some scholars suggest that hyperlinks are a tool for the new journalistic approach of curation: providing vetted, accurate sources so readers can actively seek and critically evaluate information (van der Wurff et al., 2008). Journalists have always been responsible for selecting credible sources expressing varying viewpoints; external hyperlinks are simply an extension of that process (Carpenter, 2010). Journalism has traditionally relied on official sources such as officials and institutions when covering both live and preplanned events (Cassidy, 2006; Livingston \& Bennett, 2003; Shoemaker \& Reese, 1996); those sources could be included with a simple link. Hyperlinks are also immediate (Tremayne, Weiss, \& Alves, 2007). Rather than taking the time and energy to research and report on an unfamiliar topic, reporters can write up the most current part of the story and "link to the rest" of the coverage, on their own site or another one, delivering in-depth content in a timely manner.

No research has yielded a definitive explanation for the lack of external hyperlinks in online news, but suggestions in the research fall into the two categories indicated by IDT: excess of risk and lack of advantage. News organizations may perceive no benefit unless they are able to make external hyperlinks financially profitable (Barnhurst, 2010), but the perceived risks are plentiful. External hyperlinks risk directing users away from the news organization's page, and thus away from the organization's content and the ads that fund it. They expose users to 


\section{EXTERNAL HYPERLINKING PRACTICES}

competing news sources, potentially undercutting the linking organization's own audience (Chang et al., 2012). Linking away from one's website is only appealing if others also link back to one's own site. Jarvis (2008) proposes a "link economy" with a new ethic: “This leads to a new Golden Rule of Links in journalism - link unto others' good stuff as you would have them link unto your good stuff.” The link economy can and does work (Weber, 2012), but unfortunately, the benefit of that ethic may not be apparent until a critical mass of adopters is reached (Rogers, 2003). Critical mass is particularly important in communication technology due to reciprocal interdependence: the benefits of adopting an innovation increase for both previous and future adopters as more people adopt (Rogers, 2003, p. 344). The system may fall into a catch-22, with everyone waiting for everyone else to adopt, unless an external force can reduce the perceived risk. News organizations may also shy away from including external hyperlinks because they risk being held legally responsible for the veracity of the linked content whose creation they did not oversee (Carpenter, 2010; De Maeyer, 2012; Larsson, 2013). Reporters, already overworked due to shrinking newsrooms demanding 'one-man band' journalists who perform multiple functions, may simply not have the time to spend researching valid links without jeopardizing their own jobs if they don't meet their story quotas. In any case, none of these explanations for the lack of external hyperlinks in news articles has been tested by research.

Print-based news sites as late adopters. The news industry as a whole has been reluctant to change their hyperlinking practices regarding external hyperlinks, treading water for the last decade at least. This may suggest that traditional news media, particularly print news, are late majority adopters. Online editions of print newspapers have been called "a decisive case of how established media deal with new technologies" (Boczkowski, 2004, p. 4). Traditional media 


\section{EXTERNAL HYPERLINKING PRACTICES}

approach new technologies defensively, scoping them out for threats rather than for opportunities (Nguyen, 2008). These are classic late majority adopter attitudes. Late majority adopters tend to be skeptical of innovations (Rogers, 2003). They adopt out of economic necessity or as a result of increasing peer pressure. They are closely integrated with the system, so the system norms must favor the innovation for them to adopt. Often their resources are scarcer, so the uncertainty related to an innovation must be minimal in order to justify the risk.

Boczkowski (2004) notes that newspapers resisted integrating interactive web features because they typically try to fit new media into their existing print paradigm, rather than seeking to exploit the web's full advantages. They see the future of media as "an improved, but not radically different, version of the present" (Boczkowski, 2004, p. 12). Consequently, traditional news media have historically staunchly resisted online journalistic developments such as curation, instead holding fast to the print model of only publishing original content. Even when print papers have tried to produce new media innovative projects, their end products have tended to be less innovative than those of competitors who are not tied to traditional media (Boczkowski, 2004). The traditional news media's response has been to protect the print franchise, focusing on certain short-term gains rather than taking risks that yield uncertain longterm gains. Nguyen (2008) cites Rupert Murdoch’s defensive language before the American Society of Newspaper Editors in 2005, recalling almost wistfully when most news professionals "quietly hop[ed] that this thing called the digital revolution would just limp away" (p. 101).

Traditional media are also by their very nature well-integrated into the establishment of the news industry. They are the central hub from which alternative media, including web-based news media, grew. Burkhardt \& Brass (1990) found that those closer to the center of a system were slower to adopt an innovation. Individuals within a system like the news industry or a 


\section{EXTERNAL HYPERLINKING PRACTICES}

particular newsroom may be open to innovation, but the whole unit must change in order for widespread adoption to happen. De Maeyer (2012) quotes a journalist from her study, discussing online interactivity in her news organization: "Of course the source must be clickable. So even if it's [a competitor] we must make it clickable, for $\mathrm{Ch}^{* *}$ st's sake. We have to. I fight for that. They [other journalists in the newsroom] are terribly cautious. It's awful." (p. 697). If print-based news media are late majority adopters, that innovative journalist's frustration may not decrease for some time.

Online-native news sites as innovators. Boczkowski (2004) particularly draws out the innovation adoption differences between print-based news sites and born-on-the-web sites. These online-native sites, or sites that began online and were never rooted in an offline publication or broadcast, share some traits with the innovator adopter category, which is marked by venturesomeness and tends to be at the periphery of the system it is in, in this case the news industry (Burkhardt \& Brass, 1990; Rogers, 2003).

Online-native news sites grew up at the periphery of the news industry social system (Boczkowski, 2004; Garrison, B. \& Messner, M., 2009). Online-native news started primarily in the form of news blogs (Garrison, B. \& Messner, M., 2009). These news sources had lower overhead and less reputation to uphold, making them more able to absorb a failed risk. Without the traditional media norm of a newsroom full of reporters and editors, early online-native news sources took heavy criticism from within the industry accusing them of lessening the quality of news (Garrison, B. \& Messner, M., 2009). Despite criticism from professionals, the perceived credibility of online alternative news sources from audiences has increased since they first arose (Carpenter, 2010; Chung, Nam, \& Stefanone, 2012; Garrison, B. \& Messner, M., 2009). Online news ventures also seem to be more willing to take risks, such as sites that produce no content 


\section{EXTERNAL HYPERLINKING PRACTICES}

at all and instead exclusively aggregate news from elsewhere, or sites experimenting with nonlinear news presentation (Carpenter, 2010; Chung et al., 2012; Tremayne et al., 2007). Online citizen journalism articles were found to use more hyperlinks in general than news sites run by traditional media, and are far more likely to use external hyperlinks than are traditional media (Carpenter, 2010). In fact, found the same study, online citizen journalism articles are more likely to use external hyperlinks than internal hyperlinks. These innovative strategies deviate from the traditional news business model of attracting readers or viewers to your content then placing ads in front of them to generate revenue, and thus carries with it a higher level of risk than many traditional news outlets have been willing to tolerate.

As innovators within the news industry, online-native news sites may also take the role of change agents in a decentralized diffusion model. These actors within the news industry are exploring new ways to use the tools provided by internet technology and are demonstrating their advantage and effectiveness, reducing the level of risk due to unknowns for the rest of the industry. In theory, as traditional media see the success of online-native news sites they will begin to adopt more innovative practices, such as external hyperlinking.

Incidentally, Burkhardt and Brass (1990) found that early adopters who are at the periphery of their network prior to the adoption of the innovation move closer to the center of the network after the adoption. Online-native news sites have blurred the line between professional and non-professional journalists, to the point that some have suggested that the traditional gatekeeping role of media is dead (Garrison, B. \& Messner, M., 2009). If onlinenative news sites are in fact innovators within the news industry, their steady migration to prominence through audience-perceived credibility and greater flexibility and willingness to 


\section{EXTERNAL HYPERLINKING PRACTICES}

adapt to a digital world may explain the unsettled feeling among traditional media. Their space in the center of the system may be getting crowded out by those who adopted more quickly.

\section{Three waves of online-native news sites. A}

cursory survey of the launch dates of prominent digital

native news sites yielded three waves of news sites that

appear to align with major transitions in the digital

scene (Table 1). The first wave, from 1993 to 2004,

began with the first graphical browsers (Curtis, 2013),

at the same time that many print newspapers were

launching their first websites. At that time, print-based

news sites were largely copying text directly from the

print edition to the website with little to no web

optimization. Online-native news sites from the first

wave include Slate, Gawker, and aggregators like

Yahoo! and AOL that moved to generating their own

content in 2001. Many of these sites, at their inception,

closely adhered to the print news model, writing for the

web much as one would write for a newspaper.

Gawker, for instance, aligned itself with the traditional
Table 1

Three waves of online-native news sites by launch year

\begin{tabular}{lc}
\hline Site & $\begin{array}{c}\text { Launch } \\
\text { Year }\end{array}$ \\
\hline SFGate & 1994 \\
Consortium News & 1995 \\
Salon & 1995 \\
Slate & 1996 \\
WorldNews.com & 1998 \\
Talking Points Memo & 2000 \\
The Dish & 2000 \\
Yahoo News & 2001 \\
AOL News & 2001 \\
Gawker & 2003 \\
Huffington Post & 2005 \\
Mashable & 2005 \\
Buzzfeed & 2006 \\
The Daily Beast & 2008 \\
fivethirtyeight & 2008 \\
ProPublica & 2008 \\
The Verge & 2011 \\
Quartz & 2012 \\
Syria Deeply & 2012 \\
The Intercept & 2012 \\
Vox & 2014 \\
Vice & 2014 \\
\hline
\end{tabular}

news model when they revamped their website just this year, explaining that their front page "will feel a bit more like the front page of a newspaper" (Read, 2015).

The second wave began in 2005 with the launch of digital native mogul Huffington Post and includes several of the now-established names in online news such as Mashable, the Daily 


\section{EXTERNAL HYPERLINKING PRACTICES}

Beast, and Buzzfeed. This wave coincides with the rise of social media or Web 2.0, when internet users began in earnest to take advantage of the web's possibilities for interactivity. Buzzfeed, for example, began with the mission to report "social news," specializing in creating viral content that users would spread from person to person via social media (Buzzfeed, 2014). Online-native news in this wave turns its attention to sharable media, not merely reporting the news.

The third and current wave began in 2011 after a three-year span when no new sites were found to have launched and includes a number of news operations such as Quartz, Vice, and Syria Deeply that launched with the purpose of using the full capabilities of the web for the communication of news. Mobile phones took over shortly before this wave began, and the new format pushed this wave of sites to think outside the traditional news article structure. Zach Seward of Quartz calls their products "things": They're sometimes articles, but sometimes emails or tweets or infographics or a collection of various such artifacts (Seward, 2014). This atomization breaks the traditional news story into component parts in a way that is unique to the digital format. 


\section{EXTERNAL HYPERLINKING PRACTICES}

\section{Research Purpose and Hypotheses}

This study is a preliminary exploration of the roles of print-based and second- and thirdwave online-native news sites in the diffusion process of external hyperlinks in the news industry. Identifying the key players in the diffusion process is a first step to understanding what factors influence a particular news organization to adopt or not adopt the use of external hyperlinks. The purpose of this study within the scope of hyperlink literature is to begin to develop a model that applies both gatekeeping and innovation diffusion theories to the persistent question of why online newspapers do not use external hyperlinks.

Specifically, this study explores the following questions:

RQ1: How do online-native news sites use external hyperlinks compared to printbased news sites?

RQ2: How do second-wave online-native news sites use external hyperlinks compared to third-wave sites?

Based on the research cited above, the following hypotheses are proposed:

H1: Online-native news sites will use external hyperlinks to a different extent than print-based news sites do.

H2: Within online-native sites, second-wave online-native news sites will use external hyperlinks to a different extent than third-wave sites do.

H3: There will be no difference in print-based news sites' external hyperlink usage from 2005 to 2014, during the second and third waves of online-native news.

H4: There will be a difference in second-wave news sites' external hyperlink usage between 2010 and 2014, during the third wave of online-native news. 


\section{EXTERNAL HYPERLINKING PRACTICES}

\section{Methodology}

To test the proposed hypotheses, a quantitative content analysis comparing the use of hyperlinks over time in articles from print-based and second- and third-wave online-native news sites was performed. For the purposes of this study, a hyperlink is a word or phrase within the text of a news article that links to another webpage, either within the same second-level domain name (an internal hyperlink) or to a different domain (an external hyperlink). Any hypertext located outside the immediate text of the article were excluded, including related stories, social media links, advertisements, and navigational links. This study used in-text hyperlinks, or hyperlinks within the text of an article, as a gauge of a news outlet's attitude toward content curation as a complement to content creation. The term curation is used in this study to describe a publication linking to outside sources within a particular article in order to enhance the existing story, while aggregation is used to describe publications hosting articles from other news sites without couching them within one's own content. Aggregation is closely related to curation and is another important aspect of the link economy, but is outside the scope of this study.

This study analyzed hyperlink usage in articles from five websites from each of three categories: print-based, second-wave online-native, and third-wave online-native news websites. Articles were sampled at three points in the history of online news using Google Advanced Search to target articles from the desired year: Print-based articles were collected from 2005, at the beginning of the second wave (as has been cited, ample research indicates static external hyperlink usage prior to 2005). Print-based and second-wave articles were collected from 2010, at the close of the second wave. Print-based, second-wave, and third-wave articles were collected from 2014, during the third and present wave. Ten articles from each applicable publication were randomly selected from the week of June 15 each of those three years for a total of 300 articles: 


\section{EXTERNAL HYPERLINKING PRACTICES}

50 in 2005,100 in 2010, and 150 in 2014. June was selected because it is typically an average news month (Barnhurst, 2010; Lee, Lewis, \& Powers, 2014; Tremayne et al., 2007).

Print-based sites were selected from Pew Research Center's Top 25 Newspaper Daily Editions (2013) as well-known major market newspapers. Major market papers have the most resources, relative to other papers, to invest in keeping their news operations up to date and, crucially, to enable them to take risks with an innovation such as hyperlinking (Rogers, 2003). The five print-based news sites analyzed were The New York Times, The Wall Street Journal, The Washington Post, USA Today, and the Los Angeles Times. News sites representative of the second and third waves of online natives were selected from a blend of Online News Association awards, Webby awards, and recommendations. The five sites representing the second wave are the Huffington Post, Mashable, Buzzfeed, the Daily Beast, and Fivethirtyeight. The five sites representing the third wave are Vice, Vox, Quartz, The Verge, and The Intercept.

Each article was coded for the following, detailed in the code book (Appendix A):

- Article Code

- Article URL

- Data Collection Stage - 2005, 2010, or 2014

- Category - First wave, second wave, or print

- Source - The news organization that produced the article

- Headline

- Writer

- Article Type - News, feature, sports, opinion/editorial

- Word Count

- Number of Internal Hyperlinks 


\section{EXTERNAL HYPERLINKING PRACTICES}

- Number of External Hyperlinks - News

- Number of External Hyperlinks - Other Sources

Only articles generated by the staff of the given publication were coded. This study excluded aggregated articles because they do not reflect the hyperlinking policies of the publishing site but rather of the site that produced the content. Articles that are exclusively video or images without text were excluded as well. Wire stories and community-submitted articles, while not considered aggregated articles, were excluded.

The data was coded by four trained coders, including the researcher. Intercoder reliability for each category was calculated using Cohen's kappa. Cohen's kappa results .41-.60 are considered to have moderate agreement; $.61-.80$ is substantial agreement, and .81 to .99 is nearly perfect agreement (Viera \& Garrett, 2005). All categories in this study rated .81 or above. The reliability scores for each category are as follows: Category (1.0), Source (1.0), Article Type (.810), Number of Internal Hyperlinks (.836), Number of External Hyperlinks, News (1.0), Number of External Hyperlinks, Other Sources (.904). 


\section{EXTERNAL HYPERLINKING PRACTICES}

\section{Results}

In order to test the stated hypotheses, the chi-square statistic was applied to the coded data. Chi-square is the most common form of analysis for quantitative content analysis studies. It is a descriptive statistic, in that it describes data in a meaningful way to help patterns emerge. Descriptive statistics do not indicate causation but only that a relationship exists among the variables. Chi-square is appropriate for this study because it can determine if hyperlink practices are independent of publication type or year. This statistic is more reliable than merely examining frequencies because it accounts for the level of chance involved; ten articles from a print-based news site could use fewer hyperlinks than ten articles from an online-native news site simply by chance, but chi-square incorporates the chance factor into its calculation. One limitation of chisquare is that it can only indicate independence or dependence; it cannot indicate direction, such as more or fewer hyperlinks. This study uses chi-square to answer the primary hypotheses, then uses frequency data to explore a possible direction. It should be noted that frequency reporting is not a statistical method and should not be relied upon for conclusions. The use of frequency data in this study is meant only to provide direction for future study.

Chi-square is prone to overestimate significance in small datasets, especially when the square is only $2 \times 2$. This study applies Yates' correction to all $2 \times 2$ chi-squares. Yates' correction adjusts chi-square results to be more conservative, making it more difficult to prove significance, thereby reducing the risk of overestimating statistical significance for small data. Because chisquare only indicates correlation or non-correlation, Cramer's V was also calculated. Cramer's V is an extension of the chi-square statistic that measures level of association from 0 to 1 , with $V=.25$ or higher indicating a very strong relationship, $V=.15$ to .24 a strong relationship, $V=$ .11 to .14 a moderate relationship, $V=.06$ to .10 a weak relationship, and $V<.05$ a negligible 


\section{EXTERNAL HYPERLINKING PRACTICES}

relationship (Quinnipiac University Political Science Dept). A complete table of all frequency data is included in Appendix B.

\section{Primary inquiry.}

H1: Online-native news sites will use external hyperlinks to a different extent than printbased news sites do.

H1 is supported. A chi-square comparing the number of internal and external hyperlinks used by print-based, second-wave, and third-wave sites in the 2014 sample found that the use of external hyperlinks does differ among publication types, $X^{2}(2, N=775)=94.85, p<.001$. Cramer's V indicates a very strong relationship $(V=0.3498)$. Frequency data suggests that the online-native news sites, both second- and third-wave, use external hyperlinks more than printbased news sites do. In the 2014 sample, online-native sites in this study used three times as many hyperlinks total as did print-based sites (Table 2). Second-wave sites used $203.57 \%$ more, and third-wave sites used $185.71 \%$ more. External hyperlinks accounted for $45.54 \%$ of hyperlinks in print-based news sites, less than half, while external hyperlinks made up $78.13 \%$ of total hyperlink usage for second-wave news sites (71.56\% difference) and $89.69 \%$ for third-wave sites $(96.95 \%$ difference).

Table 2

Chi-square test of independence for external hyperlink use and publication type in 2014

\begin{tabular}{lcccccc}
\hline \multicolumn{1}{c}{$\begin{array}{c}\text { Hyperlink } \\
\text { Use }\end{array}$} & \multicolumn{2}{c}{ Hyperlink Type } & $\begin{array}{c}\text { Total } \\
\text { Hyperlinks* }\end{array}$ & $\begin{array}{c}\text { Percent } \\
\text { External* }\end{array}$ & $X^{2}$ & $V$ \\
\hline Print & 51 & 61 & 112 & $45.54 \%$ & $94.85^{* *}$ & .3498 \\
Second Wave & 268 & 75 & 340 & $78.13 \%$ & & \\
Third Wave & 287 & 33 & 320 & $89.69 \%$ & & \\
\hline
\end{tabular}

Note. $* *=p<.001$

*These observations were not used in the chi-square test of independence. 


\section{EXTERNAL HYPERLINKING PRACTICES}

H2: Within online-native sites, second-wave online-native news sites will use external hyperlinks to a different extent than third-wave sites do.

$\mathrm{H} 2$ is supported. A chi-square test indicates that there is a relationship between external hyperlink usage and wave of online-native news, $X^{2}(1, N=663)=15.37, p<.001$. Cramer's V indicates a moderate relationship $(V=.1564)$. Frequency data suggests that second-wave sites used fewer external hyperlinks than third-wave sites did, despite using more total hyperlinks (Table 2).

H3: There will be no difference in print-based news sites' external hyperlink usage from 2005 to 2014, during the second and third waves of online-native news.

H3 is supported, though the findings are inconclusive. A chi-square test found a relationship between external hyperlink usage and the year of publication, indicating that external hyperlink usage differed significantly among 2005, 2010, and 2014, $X^{2}(2, N=301)=$ $16.06, p<.001$. Cramer's $\mathrm{V}$ indicates a strong relationship $(V=0.231)$. However, the frequency data is inconclusive. The raw frequencies of external hyperlinks suggest a steady increase in the number of external hyperlinks among print-based news sites, but the percentage data shows a

Table 3

Chi-square test of independence for external hyperlink use in print-based news sites over time

\begin{tabular}{|c|c|c|c|c|c|c|}
\hline \multirow{2}{*}{$\begin{array}{l}\text { Hyperlink } \\
\text { Use }\end{array}$} & \multicolumn{2}{|c|}{ Hyperlink Type } & \multirow{2}{*}{$\begin{array}{c}\text { Total } \\
\text { Hyperlinks* }\end{array}$} & \multirow{2}{*}{$\begin{array}{c}\text { Percent } \\
\text { External* }\end{array}$} & \multirow[b]{2}{*}{$X^{2}$} & \multirow[b]{2}{*}{$V$} \\
\hline & External & Internal & & & & \\
\hline 2005 & 21 & 26 & 47 & $44.68 \%$ & $16.06 * *$ & .231 \\
\hline 2010 & 33 & 109 & 142 & $23.24 \%$ & & \\
\hline 2014 & 51 & 61 & 112 & $45.54 \%$ & & \\
\hline
\end{tabular}

$*$ These observations were not used in the chi-square test of independence. 


\section{EXTERNAL HYPERLINKING PRACTICES}

sharp drop in external hyperlink usage

relative to total hyperlink usage in 2010 ,

while the 2005 and 2014 percentages are

approximately equal (Table 3 ). The

frequencies for each publication were

examined to see if the discrepancy was

due to a single anomalous publication,

but no trend could be identified. The

frequencies for each publication are

highly varied (Table 4). The Washington

Post's overall hyperlink usage shows a

gentle increase; the Wall Street Journal

drops steeply in 2010 then returns to its
Table 4

Hyperlink frequencies for individual print publications by year

\begin{tabular}{rrrr}
\hline & 2005 & 2010 & 2014 \\
\hline Washington Post & $\mathbf{1}$ & $\mathbf{2 4}$ & $\mathbf{5 6}$ \\
Internal & 0 & 19 & 33 \\
External & 1 & 5 & 23 \\
\hline Wall Street Journal & $\mathbf{2 4}$ & $\mathbf{5}$ & $\mathbf{2 3}$ \\
Internal & 21 & 5 & 15 \\
External & 3 & 0 & 8 \\
\hline USA Today & $\mathbf{3}$ & $\mathbf{6 6}$ & $\mathbf{1 8}$ \\
Internal & 2 & 58 & 7 \\
External & 1 & 8 & 11 \\
\hline New York Times & $\mathbf{1 9}$ & $\mathbf{4 1}$ & $\mathbf{1 0}$ \\
Internal & 3 & 27 & 5 \\
External & 16 & 14 & 5 \\
\hline L.A. Times & $\mathbf{0}$ & $\mathbf{6}$ & $\mathbf{5}$ \\
Internal & 0 & 0 & 1 \\
External & 0 & 6 & 4 \\
\hline
\end{tabular}

2005 level; and the New York Times and USA Today spike in 2010 before dropping once more. Measures of external hyperlink usage are no more predictable. A larger sample size may allow for more precise examination of trends within print-based hyperlink practices.

H4: There will be a difference in second-wave news sites' external hyperlink usage between 2010 and 2014, during the third wave of online-native news.

H4 is not supported. A chi-square test found no relationship between external hyperlink usage and the year of publication among second-wave news sites, $X^{2}(1, N=569)=.04, p>.1$. 


\section{EXTERNAL HYPERLINKING PRACTICES}

Table 5

Chi-square test of independence for external hyperlink use in second-wave news sites over time

\begin{tabular}{lcccccc}
\hline \multirow{2}{*}{$\begin{array}{c}\text { Hyperlink } \\
\text { Use }\end{array}$} & \multicolumn{2}{c}{ Hyperlink Type } & $\begin{array}{c}\text { Total } \\
\text { Hyperlinks* }\end{array}$ & $\begin{array}{c}\text { Percent } \\
\text { External* }\end{array}$ & $X^{2}$ & $V$ \\
\cline { 2 - 5 } 2010 & 179 & 47 & 226 & $79.20 \%$ & .04 & .0126 \\
2014 & 268 & 75 & 343 & $78.13 \%$ & & \\
\hline Note. & $* *=p>.1$ & & & & &
\end{tabular}

*These observations were not used in the chi-square test of independence.

The frequency of hyperlinking overall increases by $51.77 \%$, but the proportion of links that are external remains within one percent of $79 \%$ in each year (Table 5).

Secondary inquiry. An additional set of chi-squares was conducted to examine whether the destination of external hyperlinks is related to either publication type or year. External hyperlinks were coded as links to competitor news outlets or links to all other source material, including government and other official websites, documents, blogs, YouTube videos, reference materials like encyclopedias, etc. This study uses very broad categories to examine external hyperlink destinations because the external destinations are not the primary focus of this study but may provide a basis for in-depth studies in the future.

First, a series of chi-squares was conducted to test the relationship of link destinations to time. A chi-square test comparing external hyperlink destinations among print-based news sites over time found a relationship between external hyperlink destinations and the year of publication, $X^{2}(2, N=105)=7.77, p<.025$. Cramer's V indicates a very strong relationship $(V$ $=0.272$ ). Frequency data suggests that the proportion of external links to other news outlets is growing (Table 6), even as the proportion of total external hyperlinks to internal hyperlinks has stayed generally the same since 2005 (see H3). 


\section{EXTERNAL HYPERLINKING PRACTICES}

Table 6

Chi-square test of independence for external link destinations in print-based news sites over time

\begin{tabular}{lcccccc}
\hline External Link & \multicolumn{2}{l}{ Hyperlink Destination } & Total Ext. & Percent & & \\
Destinations & News & Non-News & Links* & News* & $X^{2}$ & $V$ \\
\hline 2005 & 0 & 21 & 21 & $0 \%$ & $7.77^{* *}$ & .272 \\
2010 & 7 & 26 & 33 & $21.21 \%$ & & \\
2014 & 15 & 36 & 51 & $29.41 \%$ & & \\
\hline Note. $* *=p<.025$ & & & & &
\end{tabular}

*These observations were not used in the chi-square test of independence.

A similar chi-square conducted on external hyperlinks from second-wave online-native news sites in 2010 and 2014 found no relationship between external hyperlink destination and publication year, $X^{2}(1, N=447)=0, p>.1$. Frequency data suggests that the proportion of external hyperlinks to other news sites remained virtually the same between 2010 and 2014 (Table 7).

A second series of chi-squares was conducted to test the relationship of link destinations among publication types at the 2014 data collection point. The test did find a relationship between publication type and link destinations, $X^{2}(2, N=606)=10.21, p<.01$, and Cramer's V indicates a moderate relationship $(V=.1298)$. Additional chi-squares found a difference between

Table 7

Chi-square test of independence for external link destinations in second-wave sites over time

\begin{tabular}{lcccccc}
\hline \multirow{2}{*}{$\begin{array}{c}\text { External Link } \\
\text { Destinations }\end{array}$} & \multicolumn{2}{c}{ Hyperlink Destination } & Total Ext. & Percent & & \\
\cline { 2 - 3 } 2010 & News & Non-News & Links* & News* & $X^{2}$ & $V$ \\
\hline 2014 & 124 & 97 & 179 & $45.81 \%$ & 0 & 0.0047 \\
\hline Note *** & 144 & 268 & $46.27 \%$ & & \\
\hline
\end{tabular}

Note. ${ }^{* *}=p>.1$

*These observations were not used in the chi-square test of independence. 


\section{EXTERNAL HYPERLINKING PRACTICES}

print-based and second-wave publications, $X^{2}(1, N=319)=4.29, p<.05$, and between printbased and third-wave publications, $X^{2}(1, N=338)=8.69, p<.01$, but not between second- and third-wave publications, $X^{2}(1, N=555)=2.22, p>.1$, suggesting that online-native news sites differ from print-based sites but not from each other in their external link destinations (Table 8). Cramer's V indicates a moderate relationship between print-based and second-wave sites $(V=$ $.1246)$ and a strong relationship between print-based and third-wave sites $(V=.1686)$. Frequency data suggests that online-native news sites link to other news sites more than print-based news sites do (Table 8).

Table 8

Chi-square test of independence for external link destinations and publication type in 2014

\begin{tabular}{lcccccc}
\hline \multirow{2}{*}{$\begin{array}{c}\text { Hyperlink } \\
\text { Use }\end{array}$} & \multicolumn{2}{c}{ Hyperlink Destination } & $\begin{array}{c}\text { Total Ext. } \\
\text { Links* }\end{array}$ & $\begin{array}{c}\text { Percent } \\
\text { News* }\end{array}$ & $X^{2}$ & $V$ \\
\cline { 2 - 5 } Print & 15 & 36 & 51 & $29.41 \%$ & $10.21^{* *}$ & .1298 \\
Second Wave & 124 & 144 & 268 & $46.27 \%$ & & \\
Third Wave & 152 & 135 & 287 & $52.96 \%$ & & \\
\hline
\end{tabular}

Note. $* *=p<.01$

*These observations were not used in the chi-square test of independence. 


\section{EXTERNAL HYPERLINKING PRACTICES}

\section{Discussion}

The main finding of this study is that online-native and print-based news sites do seem to use hyperlinks, especially external hyperlinks, differently. Online-native sites in this study, both second- and third-wave, used approximately three times as many hyperlinks total than the printbased sites did. This may suggest that online-native sites are more adept at thinking and working in hypertext, perhaps because they grew up in the midst of the web and its language is native to them. Of those hyperlinks, online-native sites used external hyperlinks more than the print-based sites did. In fact, both second- and third-wave online-native sites used more external than internal links, while print-based sites used more internal than external links.

These findings are consistent with previous research into print-based news sites' hyperlinking practices (Carpenter, 2010; De Maeyer, 2012; Dimitrova et al., 2003; Larsson, 2013; Nguyen, 2008). Print-based news sites continue to display a lack of innovative behavior related to hyperlink use, lagging behind their online-native counterparts. This behavior is consistent with the proposition that print-based news sites resemble late-majority adopters. That notion suggests that print-based sites' reticence toward external hyperlinks is due to a protective instinct that resists change until it is certain of the benefit, or at least the lack of harm. Printbased sites may be prioritizing internal links in order to protect their audience, creating a sort of digital corral to keep users near the site's content — and advertising — in hopes to preserve something closer to the traditional business model. Prioritizing external hyperlinks instead may still hold too great of a risk, as described earlier, and not enough promise of a working business model on the other side. There may still be an element of defending the print franchise as the primary enterprise and only participating in online news to deter it as a threat (Nguyen, 2008), but at this point in the digital revolution, such an attitude would be so foolish as to be unlikely. 


\section{EXTERNAL HYPERLINKING PRACTICES}

Print-based news outlets did show an increasing willingness to link to competing news outlets, which is an encouraging step toward large-scale participation in a link economy. However even in this respect, the print-based sites are not as strong as the online-native sites.

Online-natives' high level of external hyperlink use is also consistent the suggestion that they resemble innovators within the system. Boczkowski (2004) proposed that online-native news publications tend toward innovation more than traditional media publications do, and online-native sites in this study outperformed print-based sites in every measure. These results parallel those of citizen journalism sites that used more external than internal hyperlinks (Carpenter, 2010). Citizen journalism initiatives and online-native news publications share the characteristic of growing up on the periphery of the news industry, outside the traditional newsroom structure that print publications have operated under since the industry's inception. Online-native news sites grew up unencumbered by traditional news routines, which on one hand freed them to experiment with alternative models (Carpenter, 2010; Chung et al., 2012; Seward, 2014; Tremayne et al., 2007), and on the other hand exposed them to a high level of risk. This is consistent with the innovator adopter category, those who are willing to tolerate higher risk levels to achieve uncertain success (Rogers, 2003).

If external hyperlinks are the measure of success on the internet (Garrison, B. \& Messner, M., 2009), online-native news sites are notably more successful than print-based news sites. The online-natives in this study were consistently more innovative in both external hyperlink use and willingness to link to competing news outlets. These behaviors may suggest that these sites are producing quality journalism for the digital age, embracing the link economy and forging a new business model for online news. Alternatively, it may suggest that online-native sites produce less original content, instead synthesizing several articles from other news outlets, linking to the 


\section{EXTERNAL HYPERLINKING PRACTICES}

source articles, and labeling it a staff-written article in a form of exaggerated aggregation.

Online-native sites in this study did link to other news sites more than print-based sites did, but the study made no attempt to gauge level of original reporting. Linking to other news sites may suggest a lack of original reporting, or it may suggest a thriving link economy among news outlets who 'link unto each other's good stuff' (Jarvis, 2008).

This study was not designed to provide a thorough description of all five adopter categories within the news industry, but the proposed categories—-print-based sites as late majority and online-natives as innovators - appear to hold true, with the exception of onlinenatives functioning as change agents. This study's methodology cannot demonstrate causation, but if the online-native sites were change agents within the news industry, one could expect to see increased external hyperlinking among print-based sites correlating with the timeframes of the second or third waves of online-native sites. The results of this study do not reflect that correlation. There was a change in print-based sites' hyperlinking behavior correlating with the time of the second and third waves, but it was not a clear increase. In fact, there was hardly a pattern at all to print-based sites' hyperlinking behavior. The percentage of hyperlinks that were external among the group as a whole dropped sharply from $45 \%$ to $23 \%$ in 2010 before bouncing back to $46 \%$ in 2014 . Within the group, the individual publications' trajectories look like scattershot. The print-based sites seem to have reacted to some stimulus, but they did not increase as one would expect in response to a change agent.

This is not entirely shocking. The years between 2005 and 2010 were a struggle for the news industry. The internet rocked the news world in the 90 s and early 2000 s, then social media and mobile technology rocked it again in the last decade, following on the heels of steeply declining daily newspaper circulation that seems to spell the end of the traditional news business 


\section{EXTERNAL HYPERLINKING PRACTICES}

model (Goldstein, 2011). Industry leaders have begun talking about "post-disruption" journalism (Bergman, 2013; Woodruff, 2014). Print-based sites in this study may be trying to formulate what their industry will be like in this new era of journalism. The erratic results found in this study are exacerbated by having only three points in time to study. A similar study by Barnhurst (2010) found that external hyperlinking fell from $62.5 \%$ in 2001 to $1.2 \%$ in 2005 . The numbers are not directly comparable because that study used a much more generous definition of hyperlinks including e-mail and discussion links, related stories, and others. Nevertheless, it does suggest that perhaps external hyperlinking used to be higher, declined through 2005 and 2010, and perhaps is now on the rebound.

The reasons for print-based news sites' reticence toward external hyperlinking may be more complex than the risk-benefit equation that IDT describes, as well. Writers for print-based sites, because they draw from a long offline journalistic tradition, may do less of their information gathering online and do more through interviews and face-to-face contact, which are not as simple to link to as an article or a government website. Those same journalists, especially if they have been at the same publication for a long time, may not be familiar with web technology and may find locating and evaluating online sources and creating links to be difficult. In addition, as print newsrooms shrink, fewer journalists are tasked with more coverage, and journalists may feel they don't have time to find and vet additional sources to link. It is unlikely that print-based news sites are still waiting for a critical mass for the link economy to be a viable option. With online-native sites using a large number of hyperlinks with $80-90 \%$ of them external, reciprocal interdependence of communication innovations should no longer be a concern. It's possible, though highly speculative, that print-based publications may still feel that theirs is a higher form of journalism than that of online-native sites and therefore not want to 


\section{EXTERNAL HYPERLINKING PRACTICES}

enter into a linking relationship with them. Such an explanation, while not totally implausible given attitudes toward news blogs and online news ventures at their inception, is so petty as to border on the absurd. More likely, print-based news sites are directing their innovative efforts to other types of online features, such as multimedia or interactive pieces (Garrison, B. \& Messner, M., 2009; Larsson, 2013; van der Wurff et al., 2008). For instance, when Quartz-a third-wave online-native site — added a "Read Full Story" button to their mobile interface, they borrowed the idea from The New York Times (Benton, 2015).

Among online-native sites, the third wave also appears not to function as a change agent to the second wave, in that the second wave shows no significant increase in external hyperlink use correlating to the timeframe of the third wave. The second-wave sites do increase their level of overall hyperlinking to approximately the level of the third-wave sites, but their proportion of external hyperlinks does not change. This is likely not a case of non-adoption but rather a case of having already adopted. While the second-wave sites do lag slightly behind their third-wave counterparts, in 2014 their hyperlinks were $78 \%$ external. It would be difficult to argue that they have not adopted. This does highlight one difficulty in applying IDT to external hyperlinking. A definition for adoption will need to be created. Is over $50 \%$ of hyperlinks being external considered adoption? Is it a certain rate of hyperlinks per article? (The rates per article for the categories in this study were 6.40 for third-wave, 6.86 for second-wave, and 2.24 for print-based in 2014.) Is it possible to have varying levels of adoption depending on the extent of external hyperlink use? This study is exploratory in that respect, in that it provides a baseline for future studies to compare against their results.

In addition, this study provides preliminary support for the proposed three waves of online-native news sites. The second and third waves did behave differently in this study in 


\section{EXTERNAL HYPERLINKING PRACTICES}

regard to their use of external hyperlinks, though they did not behave significantly differently in regard to linking to other news sites. There appears to be a progression of innovation from the second to the third wave. The second wave is far more innovative than the print-based sites, but not quite as innovative as the third wave. The second wave does increase its number of hyperlinks to match that of the third wave, but its proportion of external hyperlinks remains a step behind. This is certainly a tenuous connection, but sufficient to warrant further research. 


\section{EXTERNAL HYPERLINKING PRACTICES}

\section{Limitations and Further Research}

The study does suffer certain limitations, mainly related to the size of the dataset and those inherent to the methodology. A similar study with a larger dataset, particularly one including more than three points in time, would yield a more precise description of the fluctuating hyperlink practices among print-based news sites noted above. Such a study may also allow for the plotting of a cumulative frequency graph that typically yields the distinctive Scurve. Researchers would also need to develop a definition of adoption, because hyperlinking is not a yes-or-no proposition, such as using or not using hybrid corn seed. Content analysis is an unusual methodology for an IDT study; usually IDT studies rely on interviews and surveys, so this study lacks some of the typical IDT results. IDT studies also often suffer from innovation bias, or the assumption that innovation is always a positive change (Rogers, Singhal, \& Quinlan, 2009). The researcher has attempted to restrain this bias, but it is a known weakness in the theory.

This study is a preliminary study, and as such its success is in that it perhaps raises more questions than it answers. A few areas for future research arising from this study are noted below.

- As mentioned above, this study should be repeated with a larger sample size and including more years, though not necessarily a longer span of time, to verify the results and make a closer examination of the external hyperlinking trends, especially of the print-based news sites.

- Technology moves fast, and even though the data is as recent as last year, some of these observations may already be out of date. Any future study should use as recent data as possible. 


\section{EXTERNAL HYPERLINKING PRACTICES}

- A study using more traditional IDT methods such as interviews and surveys could more aggressively investigate why print-based sites lag behind online natives. Understanding the motivation behind the behavior is very important in understanding what might create change.

- This study only addresses in-text links, but news sites link outside their own domain through 'related links' after articles and areas on the homepage devoted to aggregated content.

- News publications also use social media to distribute links to their own and perhaps other news outlets' articles.

- A detailed examination of the destinations of external hyperlinks would contribute significantly to the understanding of how news outlets use hyperlinks.

- Hyperlinks are only one way to demonstrate innovativeness and adaptation to the web. Print-based and online-native sites may also differ in their use of multimedia and interactive features.

- Broadcast news follows an entirely different reporting method but still posts news articles with hyperlinks online. Their use of hyperlinks should also be examined.

- The three waves of online-native news proposed here could provide a useful subcategorization of online-native news as well as describe a progression of innovation in the online news industry. These categories should be tested by research. 


\section{EXTERNAL HYPERLINKING PRACTICES}

\section{Conclusion}

As mentioned before, this study is a preliminary exploration of a largely unexplored area of research, comparing online-native and traditional media-based news sites. As such there are many questions this study does not answer. It does, however, provide several possible avenues for further research. It suggests that, in future studies, online-native and print-based news sites should be addressed separately because they do appear to behave differently. It also continues to raise the question of why print-based news sites are so far behind online-native news sites in use of hyperlinks. Many plausible reasons have been speculated upon in this and other studies, but none has been supported by research. This study does not answer that question, but it does propose a new lens through which to view the problem. Gatekeeping theory proposes that routine forces, or industry norms, are highly influential in determining what news items reach the public. Hyperlinks are both a technological practice to adopt and a news item to be evaluated and approved, and as such their road to the public eye is more complex than simply 'in' or 'out.' IDT specializes in encouraging an innovation to be adopted or routinized and identifying hindrances to that process. The answer to the elusive question of why print-based news sites have been slow to embrace hyperlinking and external hyperlinks may rest at the nexus of these two theories. 


\section{EXTERNAL HYPERLINKING PRACTICES}

\section{References}

Barnhurst, K. G. (2010). The form of reports on us newspaper internet sites, an update. Journalism Studies, 11(4), 555-566. doi:10.1080/14616701003638426

Benton, J. (2015, June 2). Quartz is trying to make its articles stickier on smartphones with a new "read full story" button. Nieman Lab

Bergman, C. (2013, Feb. 13). 5 reasons mobile will disrupt journalism like the internet did a decade ago. Poynter

Berners-Lee, T. (2014). We need a magna carta for the internet. New Perspectives Quarterly, 31(3), 39. doi:10.1111/npqu.11475

Berners-Lee, T., Shadbolt, N., \& Hall, W. (2006). The semantic web revisited. IEEE Intelligent Systems, 21(3), 96. doi:10.1109/MIS.2006.62

Boczkowski, P. J. (2004). Digitizing the news: Innovation in online newspapers. Cambridge, MA: The MIT Press.

Borah, P. (2014). The hyperlinked world: A look at how the interactions of news frames and hyperlinks influence news credibility and willingness to seek information. Journal of Computer-Mediated Communication, 19(3), 576-590. doi:10.1111/jcc4.12060

Burkhardt, M. E., \& Brass, D. J. (1990). Changing patterns or patterns of change: The effects of change in technology on social network structure and power. Administrative Science Quarterly, 35(1), 104. 


\section{EXTERNAL HYPERLINKING PRACTICES}

Buzzfeed. (2014). About. Retrieved from http://www.buzzfeed.com/about

Carpenter, S. (2010). A study of content diversity in online citizen journalism and online newspaper articles. New Media \& Society, 12(7), 1064-1084.

doi: $10.1177 / 1461444809348772$

Cassidy, W. P. (2006). Gatekeeping similar for online, print journalists. Newspaper Research Journal, 27(2), 6-23. Retrieved from http://search.ebscohost.com/login.aspx?direct=true $\& \mathrm{db}=\mathrm{a} 9 \mathrm{~h} \& \mathrm{AN}=21400691 \&$ site=ehost$\underline{\text { live }}$

Chang, T., Southwell, B. G., Lee, H., \& Hong, Y. (2012). Jurisdictional protectionism in online news: American journalists and their perceptions of hyperlinks. New Media \& Society, 14(4), 684-700. doi:10.1177/1461444811422888

Chan-Olmsted, S., Rim, H., \& Zerba, A. (2013). Mobile news adoption among young adults: Examining the roles of perceptions, news consumption, and media usage. Journalism \& Mass Communication Quarterly, 90(1), 126-147. doi:10.1177/1077699012468742

Chung, C. J., Nam, Y., \& Stefanone, M. A. (2012). Exploring online news credibility: The relative influence of traditional and technological factors. Journal of Computer-Mediated Communication, 17(2), 171-186. doi:10.1111/j.1083-6101.2011.01565.x

Curtis, A. (2013). The brief history of social media. Retrieved from http://www2.uncp.edu/home/acurtis/NewMedia/SocialMedia/SocialMediaHistory.html 


\section{EXTERNAL HYPERLINKING PRACTICES}

De Maeyer, J. (2012). The journalistic hyperlink. Journalism Practice, 6(5), 692-701. doi:10.1080/17512786.2012.667273

De Maeyer, J. (2013). Towards a hyperlinked society: A critical review of link studies. New Media \& Society, 15(5), 737-751. doi:10.1177/1461444812462851

Dimitrova, D. V., Connolly-Ahern, C., Williams, A. P., Kaid, L. L., \& Reid, A. (2003). Hyperlinking as gatekeeping: Online newspaper coverage of the execution of an american terrorist. Journalism Studies, 4(3), 401. Retrieved from http://search.ebscohost.com/login.aspx?direct=true \&db=ufh\&AN=10283050\&site=ehost$\underline{\text { live }}$

Garrison, B. \& Messner, M. (2009). Internet communication. In Salwen, M.B. \& Stacks, D.W. (Ed.), An integrated approach to communication theory and research (2nd ed., pp. 389405). New York: Routledge.

Goldstein, K. (2011). Sixty years of daily newspaper circulation trends Communications Management Inc.

Himelboim, I., Chang, T., \& McCreery, S. (2010). International network of foreign news coverage: Old global hierarchies in a new online world. Journalism \& Mass Communication Quarterly, 87(2), 297-314. Retrieved from $\underline{\text { http://search.ebscohost.com/login } . \text { aspx } ? \text { direct=true } \& d b=u f h \& A N=53728050 \& \text { site=ehost- }}$ $\underline{\text { live }}$ 


\section{EXTERNAL HYPERLINKING PRACTICES}

Hogg, N., Lomicky, C. S., \& Hossain, S. A. (2008). Blogs in the media conversation: A content analysis of the knowledge stage in the diffusion of an innovation. Web Journal of Mass Communication Research, 12

Jarvis, J. (2007). New rule: Cover what you do best. link to the rest. Retrieved from http://buzzmachine.com/2007/02/22/new-rule-cover-what-you-do-best-link-to-the-rest/

Jarvis, J. (2008). The ethic of the link layer on news. Retrieved from http://buzzmachine.com/2008/06/02/the-ethic-of-the-link-layer-on-news/

Larsson, A. O. (2013). Staying in or going out? Journalism Practice, 7(6), 738-754. doi:10.1080/17512786.2012.748514

Lee, A. M., Lewis, S. C., \& Powers, M. (2014). Audience clicks and news placement: A study of time-lagged influence in online journalism doi:10.1177/0093650212467031

Livingston, S., \& Bennett, W. L. (2003). Gatekeeping, indexing, and live-event news: Is technology altering the construction of news? Political Communication, 20(4), 363. Retrieved from http://search.ebscohost.com/login.aspx?direct=true $\& \mathrm{db}=\mathrm{a} 9 \mathrm{~h} \& \mathrm{AN}=11309170 \&$ site=ehost$\underline{\text { live }}$

Ma, L., Lee, C. S., \& Goh, D. H. (2012). Understanding news sharing in social media: An explanation from the diffusion of innovations theory. Conference Papers -- International Communication Association, , 1-31. Retrieved from 


\section{EXTERNAL HYPERLINKING PRACTICES}

http://search.ebscohost.com/login.aspx?direct=true \&db=ufh\&AN=85900443\&site=ehost$\underline{\text { live }}$

Nguyen, A. (2008). Facing "the fabulous monster". Journalism Studies, 9(1), 91-104.

doi:10.1080/14616700701768147

Pew Research Center. (2013). Top 25 newspaper daily digital editions, 2013 state of the news media. Retrieved from http://www.stateofthemedia.org/2013/newspapers-stabilizing-butstill-threatened/25-top-25-newspaper-daily-digital-editions-3/

Quinnipiac University Political Science Dept.Cramer's V correlation. Retrieved from http://faculty.quinnipiac.edu/libarts/polsci/Statistics.html

Read, M. (2015, January 12). How to read gawker in 2015. Gawker

Rogers, E. M., Singhal, A., \& Quinlan, M. M. (2009). Diffusion of innovations. In Salwen, M.B. \& Stacks, D.W. (Ed.), An integrated approach to communication theory and research (2nd ed., pp. 418). NY: Routledge.

Rogers, E. M. (2003). Diffusion of innovations (5th ed.). New York: Free Press.

Seward, Z. (2014). In Reed College of Media (Ed.), Things

Shoemaker, P., Eichholz, M., Kim, E., \& Wrigley, B. (2001). Individual and routine forces in gatekeeping. Journalism \& Mass Communication Quarterly, 78(2), 233.

Shoemaker, P., \& Reese, S. D. (1996). Mediating the message: Theories of influences on mass media content $<b r />$ (2nd ed.). White Plains, NY: Longman Publishers USA. 


\section{EXTERNAL HYPERLINKING PRACTICES}

Squires, L. (2014). From TV personality to fans and beyond: Indexical bleaching and the diffusion of a media innovation. Journal of Linguistic Anthropology, 24(1), 42-62. doi:10.1111/jola.12036

Srivastava, J., \& Moreland, J. J. (2012). Diffusion of innovations: Communication evolution and influences. Communication Review, 15(4), 294-312. doi:10.1080/10714421.2012.728420

Tremayne, M., Weiss, A. S., \& Alves, R. C. (2007). From product to service: The diffusion of dynamic content in online newspapers. Journalism \& Mass Communication Quarterly, 84(4), 825-839. Retrieved from http://search.ebscohost.com/login. aspx ?direct=true $\& d b=u f h \& A N=31706772 \&$ site $=$ ehost$\underline{\text { live }}$

van der Wurff, R., Lauf, E., Balcytien, A., Fortunati, L., Holmberg, S. L., Paulussen, S., \& Salaverría, R. (2008). Online and print newspapers in europe in 2003: Evolving towards complementarity. Communications: The European Journal of Communication Research, 33(4), 403-430. doi:10.1515/COMM.2008.026

Viera, A. J., \& Garrett, J. M. (2005). Understanding interobserver agreement: The kappa statistic. Fam Med, 37(5), 360-363.

Weber, M. S. (2012). Newspapers and the long-term implications of hyperlinking. Journal of Computer-Mediated Communication, 17(2), 187-201. doi:10.1111/j.1083-

6101.2011.01563.x 


\section{EXTERNAL HYPERLINKING PRACTICES}

Westlund, O. (2008). From mobile phone to mobile device: News consumption on the go. Canadian Journal of Communication, 33(3), 443-463. Retrieved from http://search.ebscohost.com/login. aspx ?direct=true $\& d b=u f h \& A N=35132725 \&$ site $=$ ehost$\underline{\text { live }}$

White, D. M. (1950). The "gate keeper": A case study in the selection of news. Journalism Quarterly, 27(Fall), 383-390.

Woodruff, J. (2014, Feb 3). New media models disrupt traditional journalism. PBS Newshour 


\section{EXTERNAL HYPERLINKING PRACTICES}

\section{Appendix A}

\section{Hyperlink Study Code Book}

Please use the accompanying Excel spreadsheet to code the articles that have been assigned to you. You may open the included links in whatever internet browser you are comfortable with.

Feel free to contact the researcher with questions to clarify the coding scheme outlined below, but be advised that the researcher cannot advise you which code to enter.

Below are a few keyboard shortcuts that may make the coding process quicker and easier:

CTRL+C - Copy

CTRL+V - Paste

CTRL+M - In Excel, converts pasted text to default formatting

ALT+TAB - Switches quickly between windows, such as between Excel and the web browser

Please code each article according to the following categories:

\section{- Article Code (pre-filled)}

- Code numbers are a combination of a code for the news outlet and a consecutive number. Please double-check each code for accuracy and correct as necessary.

$\begin{array}{ll}\text { New York Times } & \text { NYT } \\ \text { Wall Street Journal } & \text { WSJ } \\ \text { Washington Post } & \text { WP } \\ \text { USA Today } & \text { USA } \\ \text { L.A. Times } & \text { LA } \\ \text { Huffington Post } & \text { HP } \\ \text { Mashable } & \text { MA } \\ \text { Buzzfeed } & \text { BF } \\ \text { The Daily Beast } & \text { DB } \\ \text { Fivethirtyeight } & \text { FTE } \\ \text { Vice } & \text { VIC } \\ \text { Vox } & \text { VOX } \\ \text { Quartz } & \text { QZ } \\ \text { The Verge } & \text { VER } \\ \text { The Intercept } & \text { INT }\end{array}$




\section{- Article URL (pre-filled)}

O Click this link to access the article to be coded in that row. If the link does not open by clicking, copy and paste the contents of this box into the address bar of your browser.

- Stage (pre-filled)

○ Indicates from which data collection wave the article was drawn.

- $1-2005$

- $2-2010$

- $3-2014$

\section{- Category}

Enter one of the following:

○ P - (Print) New York Times, Wall Street Journal, Washington Post, USA Today, L.A. Times

- S - (Second) Huffington Post, Mashable, Buzzfeed, Daily Beast, Fivethirtyeight

○ T-(Third) Vice, Vox, Quartz, The Verge, The Intercept

\section{- Source}

○ The name of the news outlet that produced the article.

- Select one of the fifteen sources listed above. If the article appears to be from another site, examine the web address to determine which source it is most closely related to.

\section{- Headline}

- The title of the article

- Writer

○ The name(s) of the individual (or group) who wrote the article

\section{- Article Type}

Some news sources may help you select which article type by indicating it in the heading of the site or in a small tag at the top of the article. If not, some light skimming may be required.

Select one of the following:

○ News 


\section{EXTERNAL HYPERLINKING PRACTICES}

- An informational or analytical article about "hard news" topics such as politics, natural disasters, financial topics, and foreign affairs.

○ Feature

- A human interest story on topics such as celebrity news, entertainment, food, religion, and travel.

○ Sports

- The article primarily relates to athletics, athletes, or an athletic event. Both news and analysis are included.

○ Op-ed

- Opinion-editorial, or an article that presents an argument for a particular view and shows a clear preference for one side over another. Op-eds can often be distinguished from news articles by examining the first and last paragraphs, where the author is likely to state his or her main point.

\section{- Word Count}

- The number of words in the article, not including the headline.

- Photo captions, author bios, advertisements, and other extraneous text is excluded. Subheaders within the article and footnotes are included in the word count.

o Suggested method: Copy and paste the text of the article into a Word document, delete any of the extraneous text mentioned above, and check the word count in the bottom left corner.

The following sections involve counting hyperlinks within an article. This study is only counting hyperlinks that are embedded within the text of an article. These hyperlinks are typically indicated by underlining and/or a different color of text, like this. Be careful; sometimes hyperlinks are subtle. When in doubt, roll your mouse cursor over the text in question.

Hyperlinks such as social media links, related articles, "see also" links, links to footnotes, and advertisements will not be coded. Also exclude links that are within images of social media posts embedded within an article, such as an image of a Tweet that includes links.

If a hyperlink is near the article but you're not sure if it's part of the article, use this rule of thumb: If the hyperlink provides more information directly related to the article, it's probably included in the study. If the hyperlink links to information that is not related or only slightly related to the story, it is probably not included in the study.

Suggested method for the following sections: Right-click on each hyperlink and select "Open in new tab" so that all link destinations can be viewed side by side.

All boxes should be filled. If there are no applicable hyperlinks, enter a zero. If two hyperlinks in the same story link to the same web page, it counts as two hyperlinks. 


\section{EXTERNAL HYPERLINKING PRACTICES}

\section{- Number of internal hyperlinks}

o The number of hyperlinks in the article that link to webpages that are within the news outlet's own website, such as a Washington Post article linking to another Washington Post article. The domain name (www.THIS_PART.com) will be the same as the original article.

\section{- Number of external hyperlinks by category}

- External hyperlinks connect to webpages that are outside of the news outlet's website, such as a Washington Post article linking to any website that is not the Washington Post. The domain name will be different from the original article.

o Please enter how many hyperlinks lead to each destination category:

- News - Links to a competing news outlet, including those in this study or any other news outlet. New or non-traditional news outlets are also included in this category.

- Official Sources - Websites for a formal organization, such as a government website, the website of a business, or an individual's professional website. This also includes reputable knowledge sources such as encyclopedias. Think of these sites as official spokespeople who represent a business, agency, or person.

- Unofficial Sources - Websites that give information but with no formal credentials, such as Wikipedia, personal blogs, or social media.

- Buy - Websites where one may purchase a given item, such as Amazon or iTunes.

- Media - Websites that present audio, video, or photographic exhibits, documents, etc., such as YouTube, SoundCloud, or Flickr. 


\section{EXTERNAL HYPERLINKING PRACTICES}

Appendix B

Summary of frequency data for each year, publication type, and publication.

\begin{tabular}{|c|c|c|c|c|c|c|c|}
\hline & & $\begin{array}{l}\text { Hyperlinks, } \\
\text { Total }\end{array}$ & $\begin{array}{l}\text { Hyperlinks, } \\
\text { Internal }\end{array}$ & $\begin{array}{c}\text { Hyperlinks, } \\
\text { External }\end{array}$ & $\begin{array}{l}\text { Hyperlinks, } \\
\text { Ext - News }\end{array}$ & $\begin{array}{l}\text { Hyperlinks, } \\
\text { Ext - Other }\end{array}$ & Word Count \\
\hline \multirow[t]{6}{*}{2005} & Print & 47 & 26 & 21 & 0 & 21 & 52995 \\
\hline & L. A. Times & 0 & 0 & 0 & 0 & 0 & 7347 \\
\hline & New York Times & 19 & 3 & 16 & 0 & 16 & 8105 \\
\hline & USA Today & 3 & 2 & 1 & 0 & 1 & 11379 \\
\hline & WSJ & 24 & 21 & 3 & 0 & 3 & 13640 \\
\hline & Washington Post & 1 & 0 & 1 & 0 & 1 & 12524 \\
\hline \multirow[t]{12}{*}{2010} & Print & 142 & 109 & 33 & 7 & 26 & 49860 \\
\hline & L. A. Times & 6 & 0 & 6 & 0 & 6 & 9694 \\
\hline & New York Times & 41 & 27 & 14 & 0 & 14 & 9956 \\
\hline & USA Today & 66 & 58 & 8 & 5 & 3 & 7683 \\
\hline & WSJ & 5 & 5 & 0 & 0 & 0 & 11304 \\
\hline & Washington Post & 24 & 19 & 5 & 2 & 3 & 11223 \\
\hline & Second-wave & 226 & 47 & 179 & 82 & 97 & 30517 \\
\hline & Buzzfeed & 14 & 3 & 11 & 2 & 9 & 1311 \\
\hline & Daily Beast & 78 & 11 & 67 & 45 & 22 & 12179 \\
\hline & Fivethirtyeight & 61 & 6 & 55 & 12 & 43 & 11016 \\
\hline & Huffington Post & 34 & 9 & 25 & 19 & 6 & 3673 \\
\hline & Mashable & 39 & 18 & 21 & 4 & 17 & 2338 \\
\hline \multirow[t]{18}{*}{2014} & Print & 112 & 61 & 51 & 15 & 36 & 38871 \\
\hline & L. A. Times & 5 & 1 & 4 & 0 & 4 & 8522 \\
\hline & New York Times & 10 & 5 & 5 & 0 & 5 & 12142 \\
\hline & USA Today & 18 & 7 & 11 & 2 & 9 & 3359 \\
\hline & WSJ & 23 & 15 & 8 & 0 & 8 & 7578 \\
\hline & Washington Post & 56 & 33 & 23 & 13 & 10 & 7270 \\
\hline & Second-wave & 343 & 75 & 268 & 124 & 144 & 33187 \\
\hline & Buzzfeed & 52 & 8 & 44 & 32 & 12 & 4923 \\
\hline & Daily Beast & 67 & 8 & 59 & 24 & 35 & 11744 \\
\hline & Fivethirtyeight & 118 & 31 & 87 & 27 & 60 & 9389 \\
\hline & Huffington Post & 42 & 7 & 35 & 18 & 17 & 3524 \\
\hline & Mashable & 64 & 21 & 43 & 23 & 20 & 3607 \\
\hline & Third-wave & 320 & 33 & 287 & 152 & 135 & 31411 \\
\hline & Quartz & 79 & 7 & 72 & 44 & 28 & 5562 \\
\hline & The Intercept & 111 & 3 & 108 & 61 & 47 & 11527 \\
\hline & The Verge & 23 & 6 & 17 & 7 & 10 & 3102 \\
\hline & Vice & 42 & 7 & 35 & 12 & 23 & 6031 \\
\hline & Vox & 65 & 10 & 55 & 28 & 27 & 5189 \\
\hline
\end{tabular}

